\title{
Epidemiology and long term prognosis of hepatitis $C$ virus infection in Japan
}

\author{
M Yano, H Yatsuhashi, O Inoue, $\mathrm{K}$ Inokuchi, M Koga
}

\begin{abstract}
In Japanese blood donors, positivity for antibodies to hepatitis $\mathrm{C}$ virus (HCV) ranges from $0 \cdot 2 \%$ in subjects under 20 to $3.9 \%$ in those over 50 years. It is estimated that at least $2 \cdot 3$ million Japanese have contracted HCV infection through contaminated blood. HCV carrier state was confirmed by polymerase chain reaction for HCV-RNA in subjects positive for antibodies to more than one viral protein (70\% of cases). Subjects positive for core antibody alone, however, were found to be HCV-RNA negative with normal liver function, and are considered to have only a past history of $\mathrm{HCV}$ infection $(30 \%$ of cases). Acute hepatitis $\mathrm{C}$ progresses to chronic infection in about $90 \%$ of cases. In comparison with hepatitis $B$, chronic hepatitis $C$ leads more frequently to cirrhosis and liver cancer, and rarely remits spontaneously. In typical HCV infection, aminotransferase activities fluctuate markedly in the early stages, then become relatively stable for 10 years or more, with chronic persistent hepatitis shown by histological examination. Thereafter, aminotransferase activities may change dramatically, with progression to chronic active hepatitis and rapid development of cirrhosis and hepatocellular carcinoma. On average, it takes about 30 years for chronic hepatitis $C$ to progress from initial infection to cirrhosis and cancer, but the disease progresses much more rapidly in elderly patients. (Gut 1993; supplement: S13-S16)
\end{abstract}

Epidemiology of HCV infection in Japan From December 1990, screening for antihepatitis C virus (HCV) antibody in donor

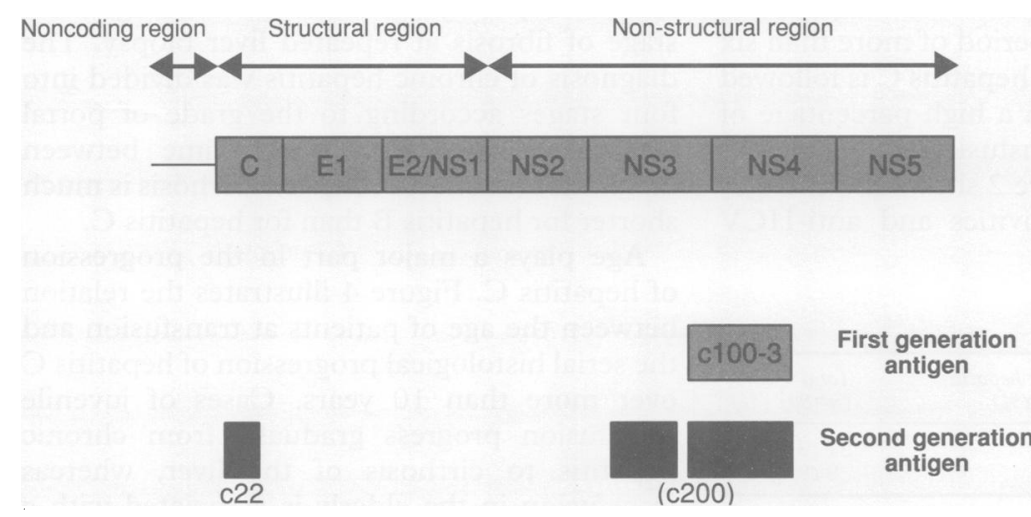

Figure 1 HCV genome and antigens. blood was carried out in blood banks across Japan using first generation enzyme linked immunosorbent assays (ELISAs) for antiHCV. ${ }^{1-3}$ In February 1992, this screening procedure was changed to a new one using the second generation anti-HCV assay that works on the principle of passive haemaggluination. This is because the first generation assay, the anti-c100-3 antibody-detecting ELISA, has a low sensitivity and leads to a number of false positives. The second generation anti-HCV assay uses three epitopes, namely core region $\mathrm{c} 22$, non-structural region $\mathrm{c} 33 \mathrm{c}$, and the c100-3 antigen used in the first generation kit (Fig 1). The sensitivity and specificity of HCV detection have been improved appreciably by this new ELISA, together with supplementary testing by recombinant immunoblot assay (RIBA). ${ }^{4}$ Table I lists the number of Japanese blood donors positive for anti-HCV antibodies, as determined by second generation assays. Anti-HCV positivity is clearly age dependent in Japan; in subjects under 20 years, the prevalence is as low as $0.2 \%$ whereas in those over 50 the prevalence is as high as $3 \cdot 9 \%$. In Japan, it is estimated that 2.3 million have contracted the infection through contaminated blood. The actual number of anti-HCV positive persons may be even higher than $2 \cdot 3$ million, as people over 65 have not been included in the figures (as they are no longer eligible to donate blood), and these older donors have a higher rate of positivity compared with younger ones.

\section{Anti-HCV positive patients and $\mathrm{HCV}$ carriers}

Are all second generation anti-HCV positive patients HCV carriers? Table II shows the results of a survey of 537 medical professionals, divided into three groups: those positive for HCV by c100-3 ELISA alone (cases 1-3); those positive for anti-HCV by both first and second generation assays (cases 4-10); and those positive for core antibody alone (cases 11-16). In this study, those anti-HCV positive by the first generation assay alone were found to be negative when tested for anti-HCV by RIBA and for HCV-RNA by polymerase chain reaction (PCR) techniques. Neither RIBA nor PCR was able to prove the relation with $\mathrm{HCV}$, and so these are presumed to be false positive results. In almost all the people positive by both the first and second generation assays, antibodies were also detected by RIBA, and HCV-RNA was detected on PCR, and they were therefore considered to be $\mathrm{HCV}$ carriers. All cases who were positive for the core 
TABLE I Number (\%) of people estimated anti-HCV positive ${ }^{\star}$ in Fapan

\begin{tabular}{lllllll}
\hline Age $(y)$ & $0-20$ & $21-30$ & $31-40$ & $41-50$ & Over 51 & Total \\
\hline Population of age group (millions) & $35 \cdot 013$ & 16.024 & $19 \cdot 792$ & $17 \cdot 372$ & $32 \cdot 807$ & $121 \cdot 008$ \\
Number anti-HCV positive (millions) & 0.085 & 0.118 & 0.373 & 0.452 & $1 \cdot 294$ & 2.323 \\
Anti-HCV positive (\%)t & 0.2 & 0.7 & 1.9 & 2.6 & 3.9 & 1.9 \\
\hline
\end{tabular}

«Tested by second generation assay.

†Based on blood donors in Sasebo and Saga blood centre.

TABLE II Pattern of reactivity to various HCV epitopes in $16 \mathrm{HCV}$ positive patients among 537 medical professionals

\begin{tabular}{|c|c|c|c|c|c|c|c|c|c|c|c|c|}
\hline \multirow[t]{2}{*}{$N$} & \multirow{2}{*}{$\begin{array}{l}c 100(\mathrm{Or}) \\
\mathrm{COI}\end{array}$} & \multirow{2}{*}{$\begin{array}{l}c 100(A b) \\
C O I\end{array}$} & \multirow{2}{*}{$\begin{array}{l}\text { Po } \\
\text { COI }\end{array}$} & \multirow{2}{*}{$\begin{array}{l}\not{f C C} \\
\mathrm{COI}\end{array}$} & \multirow{2}{*}{$\begin{array}{l}K C L \\
C O I\end{array}$} & \multicolumn{4}{|c|}{$R I B A(2 n d)$} & \multirow{2}{*}{$\begin{array}{l}H C V-R N A \\
P C R\end{array}$} & \multicolumn{2}{|l|}{$2 n d$} \\
\hline & & & & & & 511 & $c 100-3$ & $c 33 c$ & $c 22-3$ & & $R I A$ & $E I A$ \\
\hline 1 & $1 \cdot 2$ & 0.7 & 0.4 & 0.3 & 0.1 & $(-)$ & $(-)$ & $(-)$ & $(-)$ & $(-)$ & 0.0 & 1.6 \\
\hline 2 & $1 \cdot 1$ & 0.6 & 0.3 & 0.2 & 0.2 & $(-)$ & $(-)$ & $(-)$ & $(-)$ & $(-)$ & 0.0 & $1 \cdot 2$ \\
\hline 3 & 1.6 & $1 \cdot 0$ & 0.3 & 0.1 & 0.2 & $(-)$ & $(-)$ & $(-)$ & $(-)$ & $(-)$ & 0.8 & $4 \cdot 0$ \\
\hline 4 & 5.0 & $3 \cdot 1$ & 0.4 & 1.8 & 0.3 & $(-)$ & $2+$ & $(-)$ & $1+$ & $(-)$ & 1.4 & $5 \cdot 8$ \\
\hline 5 & $2 \cdot 3$ & $2 \cdot 3$ & 4.8 & 3.4 & $2 \cdot 8$ & $(-)$ & $(-)$ & $2+$ & $2+$ & $(-)$ & $5 \cdot 3$ & 5.8 \\
\hline 6 & 5.9 & $2 \cdot 9$ & $1 \cdot 1$ & 8.6 & $11 \cdot 0$ & $1+$ & $(-)$ & $4+$ & $4+$ & $(+)$ & 11.9 & $5 \cdot 8$ \\
\hline 7 & $6 \cdot 4$ & $3 \cdot 3$ & $5 \cdot 3$ & $10 \cdot 1$ & 5.6 & $1+$ & $4+$ & $4+$ & $4+$ & $(+)$ & $14 \cdot 8$ & $5 \cdot 8$ \\
\hline 8 & $6 \cdot 4$ & $3 \cdot 3$ & $4 \cdot 2$ & 9.5 & $1 \cdot 3$ & $3+$ & $4+$ & $4+$ & $4+$ & $(+)$ & $13 \cdot 2$ & 5.8 \\
\hline 9 & $6 \cdot 4$ & $3 \cdot 3$ & $2 \cdot 4$ & $10 \cdot 1$ & $7 \cdot 4$ & $4+$ & $4+$ & $4+$ & $4+$ & $(+)$ & $13 \cdot 3$ & 5.8 \\
\hline 10 & 0.4 & $1 \cdot 4$ & 1.4 & $5 \cdot 1$ & $1 \cdot 1$ & $(-)$ & $(-)$ & $(-)$ & $2+$ & $(-)$ & 1.6 & $5 \cdot 8$ \\
\hline 11 & $0 \cdot 1$ & 0.3 & $1 \cdot 6$ & $8 \cdot 6$ & 0.3 & $(-)$ & $(-)$ & $(-)$ & $3+$ & $(-)$ & $1 \cdot 8$ & $5 \cdot 8$ \\
\hline 12 & 0.1 & 0.5 & 1.7 & 2.9 & 0.2 & $(-)$ & $(-)$ & $(-)$ & $2+$ & $(-)$ & $4 \cdot 1$ & $5 \cdot 8$ \\
\hline 13 & 0.2 & 0.7 & 1.8 & 4.5 & 0.6 & $(-)$ & $(-)$ & $(-)$ & $2+$ & $(-)$ & 1.8 & $5 \cdot 8$ \\
\hline 14 & $0 . \overline{2}$ & 0.6 & $2 \cdot 8$ & 6.4 & 0.6 & $(-)$ & $(-)$ & $(-)$ & $4+$ & $(-)$ & 3.9 & $5 \cdot 8$ \\
\hline 15 & $0 \cdot \overline{1}$ & 0.5 & $2 \cdot 5$ & $4 \cdot 3$ & 0.4 & $(-)$ & $(-)$ & $(-)$ & $2+$ & $(-)$ & 1.5 & $5 \cdot 8$ \\
\hline 16 & $0 \cdot 2$ & $0 \cdot 7$ & 0.8 & 1.5 & 0.7 & $(-)$ & $(-)$ & $(-)$ & $2+$ & $(-)$ & $1 \cdot 3$ & 5.5 \\
\hline
\end{tabular}

antibody alone, however, were found to be free from HCV-RNA and had clinically normal liver function. These patients were considered to have a past history of $\mathrm{HCV}$ infection. From these findings, it can be assumed that of the $2 \cdot 3$ million anti-HCV positive cases in Japan, about $70 \%$ are carriers of the virus, and the remaining $30 \%$ have only a past history of infection.

\section{Course of $\mathrm{HCV}$ infection}

The typical clinical course of HCV infection can be understood from the clinical course of post-transfusion NANB hepatitis, in which the time of infection is clearly recorded. Eighty nine cases of acute hepatitis $C$ have been followed up for more than one year (Table III). After a given period of latency after transfusion, the infection follows a typical course of acute hepatitis, with increased serum values of alanine and aspartate aminotransferase activities (ALT and AST, respectively), and the onset of jaundice. Subsequently, liver function and symptoms either improve gradually with time, or the disease worsens repeatedly and moves into a transitional stage. Liver function returns to normal within six months in $7 \cdot 7 \%$ of patients, and deteriorates over a period of more than six months in $92.3 \%$. Acute hepatitis $\mathrm{C}$ is followed by persistent hepatitis in a high percentage of patients with either transfusion associated or sporadic infection. Figure 2 shows the changes in aminotransferase activities and anti-HCV

TABLE III Persistence of acute hepatitis $C$

\begin{tabular}{llll}
\hline & $\begin{array}{l}\text { Post-transfusion hepatitis } \\
(n=78)(\%)\end{array}$ & $\begin{array}{l}\text { Sporadic hepatitis } \\
(n=11)(\%)\end{array}$ & $\begin{array}{l}\text { Total } \\
(n=89)(\%)\end{array}$ \\
\hline $\begin{array}{l}\text { Persistence* } \\
\text { Return to normal† }\end{array}$ & $72(92 \cdot 3)$ & $9(81 \cdot 8)$ & $81(91 \cdot 0)$ \\
\hline
\end{tabular}

${ }^{\star}$ Liver function deteriorates over a period of more than six months.

tLiver function returns to normal within six months. values for a typical patient with hepatitis C infection. After fluctuating changes in ALT values and AST activities at an early stage of infection, the hepatitis enters a relatively stable period. Thereafter, dramatic changes in ALT and AST may follow after five or 10 years, with progression to cirrhosis of the liver. Figure 2 shows that patients progressed from chronic persistent hepatitis to chronic active hepatitis 2A (moderate), chronic active hepatitis 2B (severe), and eventually to cirrhosis of the liver. Careful study of the clinical course from onset of infection to cirrhosis and liver cancer indicates that hepatitis $\mathrm{C}$ is typified by constant improvements and exacerbations in both symptoms and liver function tests.

Figure 3 compares 22 cases of hepatitis C with 30 cases of hepatitis B in terms of clinical staging using liver biopsies, on three or more occasions over 15 years. In typical cases of hepatitis C, chronic persistent hepatitis continues for more than 10 years after the onset of disease, after which it progresses rapidly through chronic active hepatitis to cirrhosis of the liver. In contrast, most cases of hepatitis B advance to hepatic cirrhosis within four or five years of the diagnosis of chronic hepatitis. Table IV shows the progression of chronic hepatitis to cirrhosis, according to the stage of fibrosis at repeated liver biopsy. The diagnosis of chronic hepatitis was divided into four stages according to the grade of portal fibrosis. It is clear that the time between diagnosis and onset of hepatic cirrhosis is much shorter for hepatitis B than for hepatitis C.

Age plays a major part in the progression of hepatitis C. Figure 4 illustrates the relation between the age of patients at transfusion and the serial histological progression of hepatitis C over more than 10 years. Cases of juvenile transfusion progress gradually from chronic hepatitis to cirrhosis of the liver, whereas transfusion in the elderly is associated with a more rapid progression to liver cirrhosis. Thus, 


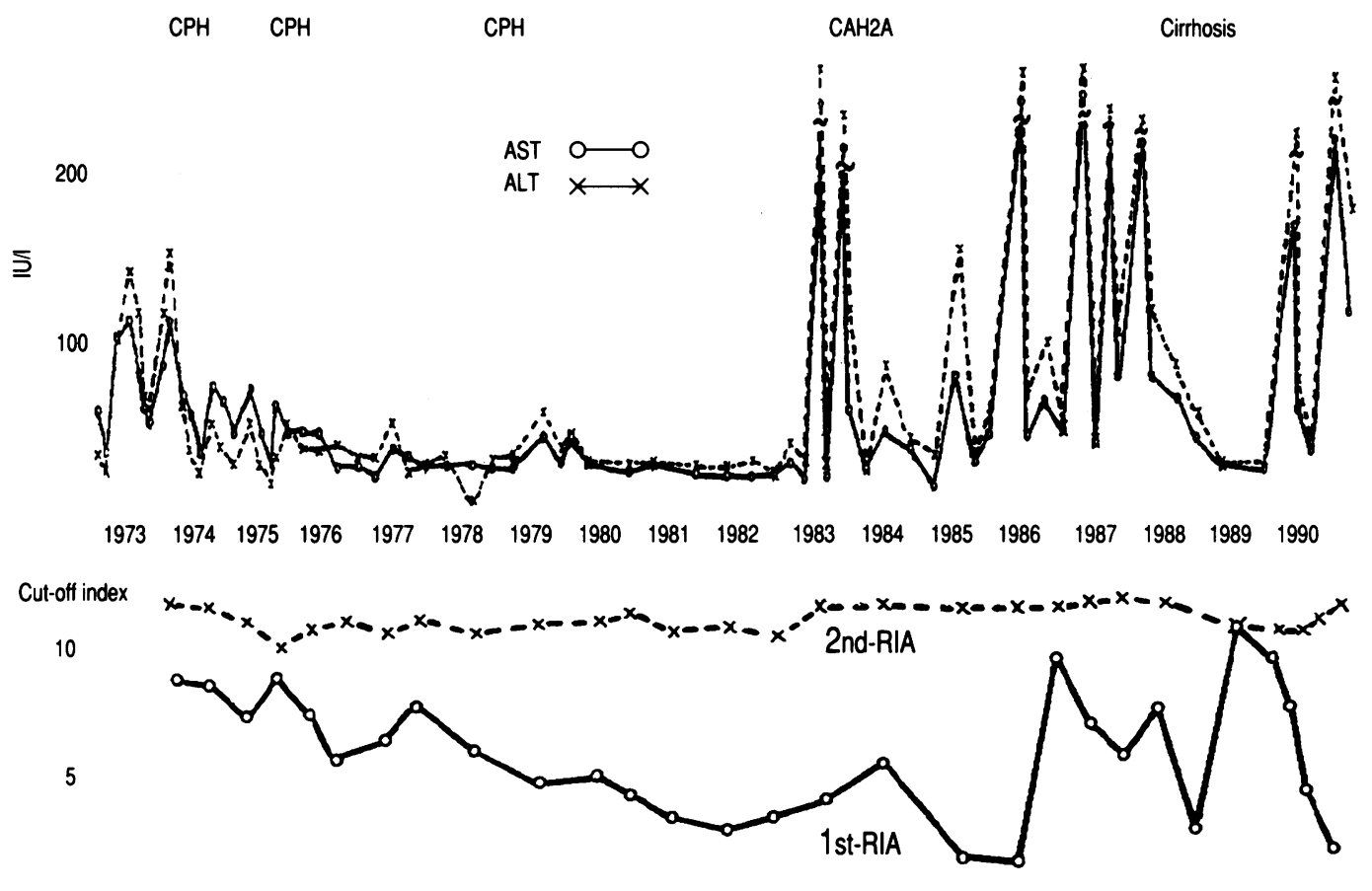

Figure 2 Changes in serum aminotransferase activities and anti-HCV values (first and second generation anti-HCV RIA kit) for a typical patient with chronic hepatitis $C$.

Hepatitis C $\quad[n=22] \quad \begin{aligned} & \text { oblood transfusion }[+] \\ & \text { oblood transfusion [-] }\end{aligned}$

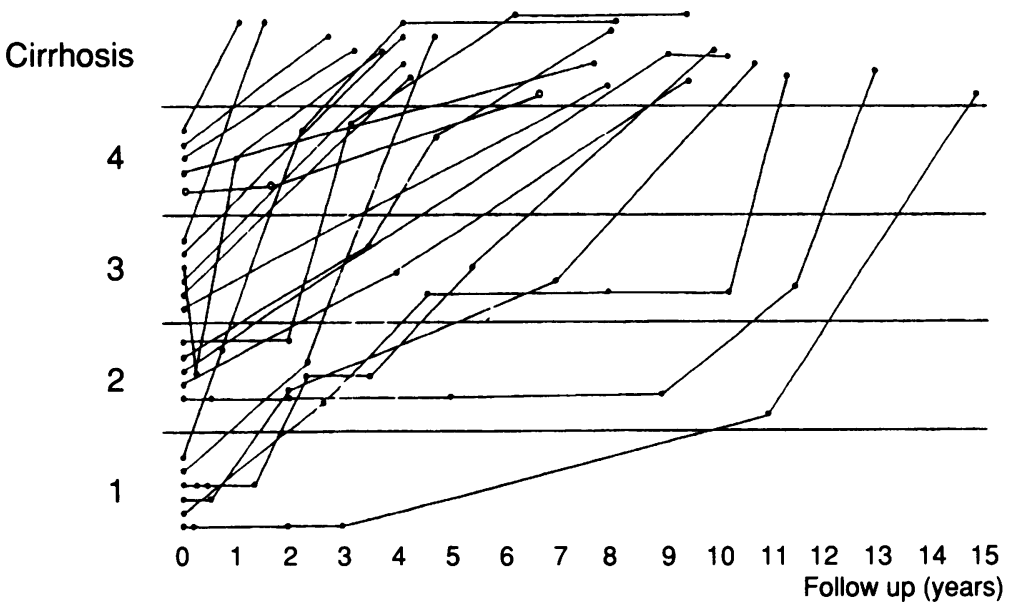

Hepatitis $\mathrm{B} \quad[n=30]$

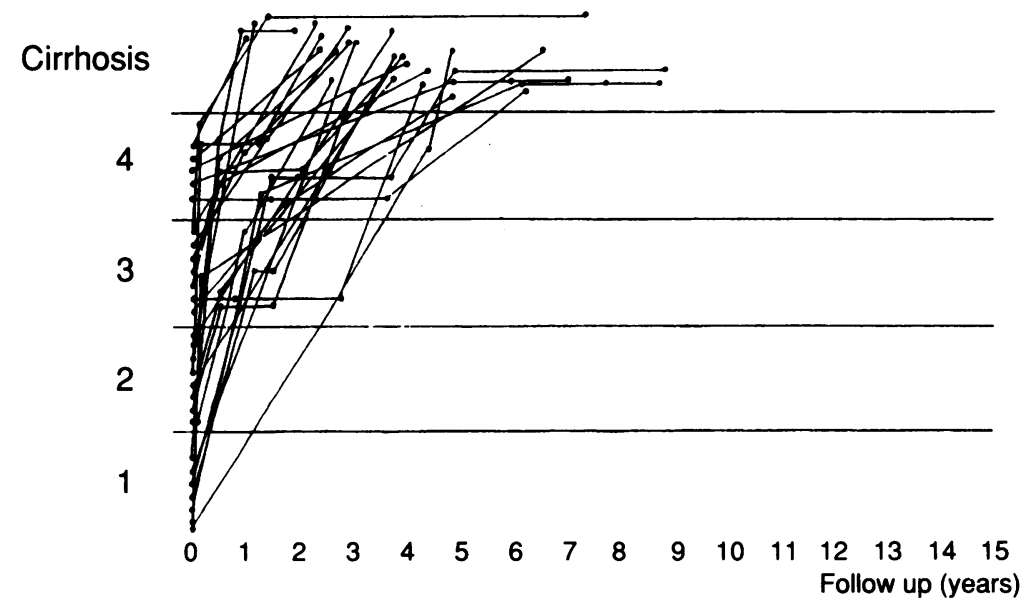

Figure 3 Relation between histological progression to liver cirrhosis and follow up period in chronic hepatitis $C$ (top) and $B$ (bottom). the host's response to $\mathrm{HCV}$ infection seems to vary greatly with age.

Long term prognosis of hepatitis $C$

Table $\mathrm{V}$ presents figures for the long term prognosis of 155 cases of chronic hepatitis C, and 173 cases of chronic hepatitis $B$ (positive for hepatitis $\mathrm{B}$ e antigen ( $\mathrm{HBeAg}$ ) at the first examination). Patients were followed up for an average study period of 8.7 years. Chronic hepatitis $\mathrm{C}$ progressed to liver cirrhosis and liver cancer in $29.7 \%$ and $14.8 \%$ of cases, respectively. Only $2.6 \%$ of patients were considered clinically cured. Of the 173 cases with chronic hepatitis $\mathrm{B}, 17 \cdot 3 \%$ progressed to cirrhosis of the liver and $4.6 \%$ to liver cancer, while $38.2 \%$ were cured. Thus, there seems to be two distinct types of chronic hepatitis B: one progresses to liver cirrhosis or cancer, while the other remits spontaneously. In contrast, very few cases of hepatitis $C$ are cured naturally,

TABLE IV Time taken for progression to cirrhosis from various histological stages of chronic viral hepatitis (years, mean (SD))

\begin{tabular}{lcl}
\hline Stage of fibrosis & $\begin{array}{l}\text { Hepatitis } C \\
(n=23)\end{array}$ & $\begin{array}{l}\text { Hepatitis } B \\
(n=30)\end{array}$ \\
\hline 1 (Fibrous portal expansion limited to & $12 \cdot 1(4 \cdot 8)$ & $4 \cdot 4(1 \cdot 8)$ \\
the portal zone) & & \\
2 (Portal elongation but no bridging & $8 \cdot 2(2 \cdot 7)$ & $3 \cdot 3(1 \cdot 4)$ \\
fibrosis) & $5 \cdot 2(3 \cdot 5)$ & $3 \cdot 5(1 \cdot 4)$ \\
4 (Partial bridging fibrosis) & $4 \cdot 4(2 \cdot 6)$ & $2 \cdot 6(1 \cdot 5)$ \\
\hline
\end{tabular}

TABLE v Long term prognosis of chronic hepatitis $C$ and $B$

\begin{tabular}{lll}
\hline Prognosis & $\begin{array}{c}\text { Hepatitis } C \\
(n=155)(\%)\end{array}$ & $\begin{array}{c}\text { Hepatitis } B \\
(n=173)(\%)\end{array}$ \\
\hline Cirrhosis & $46(29 \cdot 7)$ & $30(17 \cdot 3)$ \\
Hepatocellular carcinoma & $23(14 \cdot 8)$ & $8(4 \cdot 6)$ \\
Clinical cure & $4(2 \cdot 6)$ & $66(38 \cdot 2)$ \\
\hline
\end{tabular}




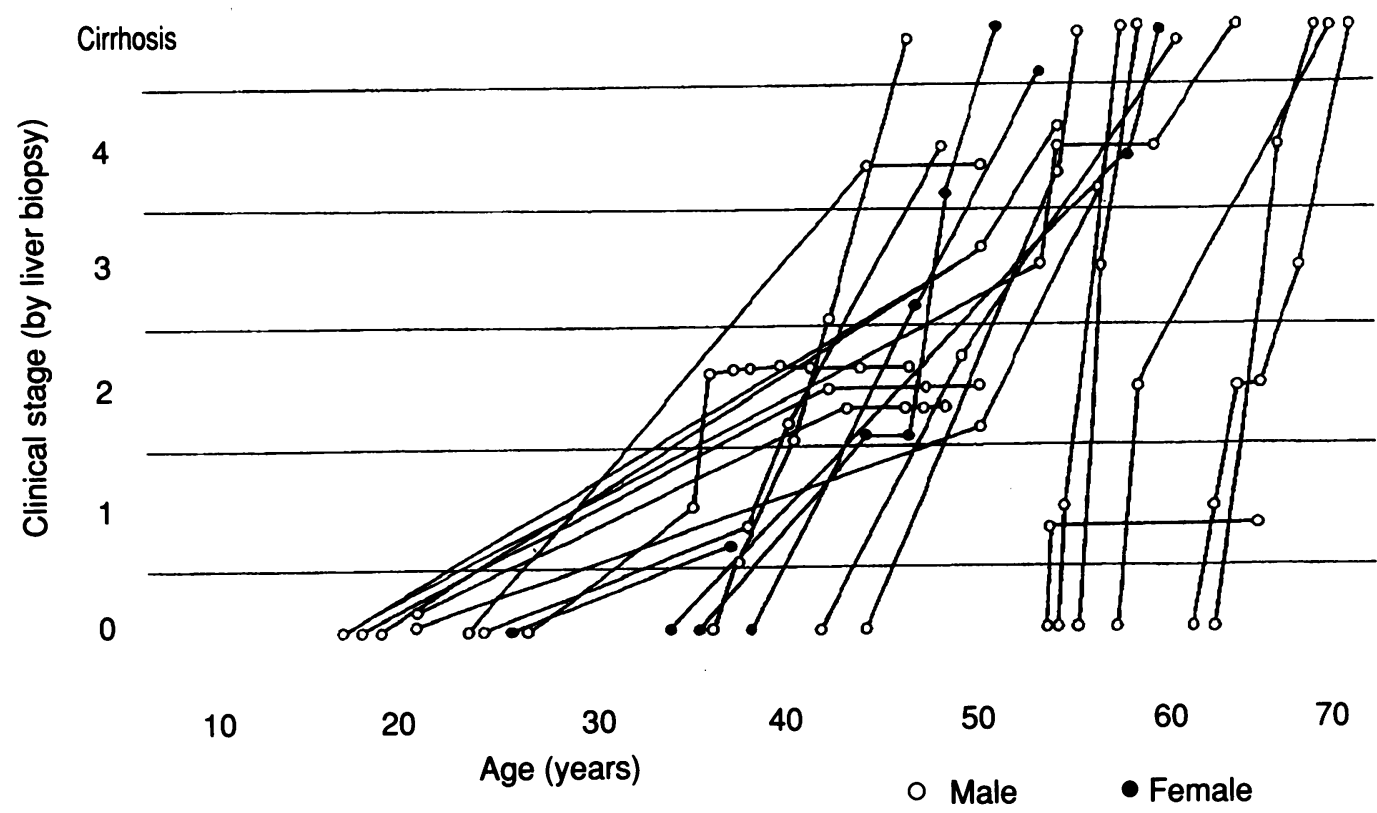

Figure 4 Relation between the age at transfusion and histological progression of hepatitis $C$ over more than 10 years.

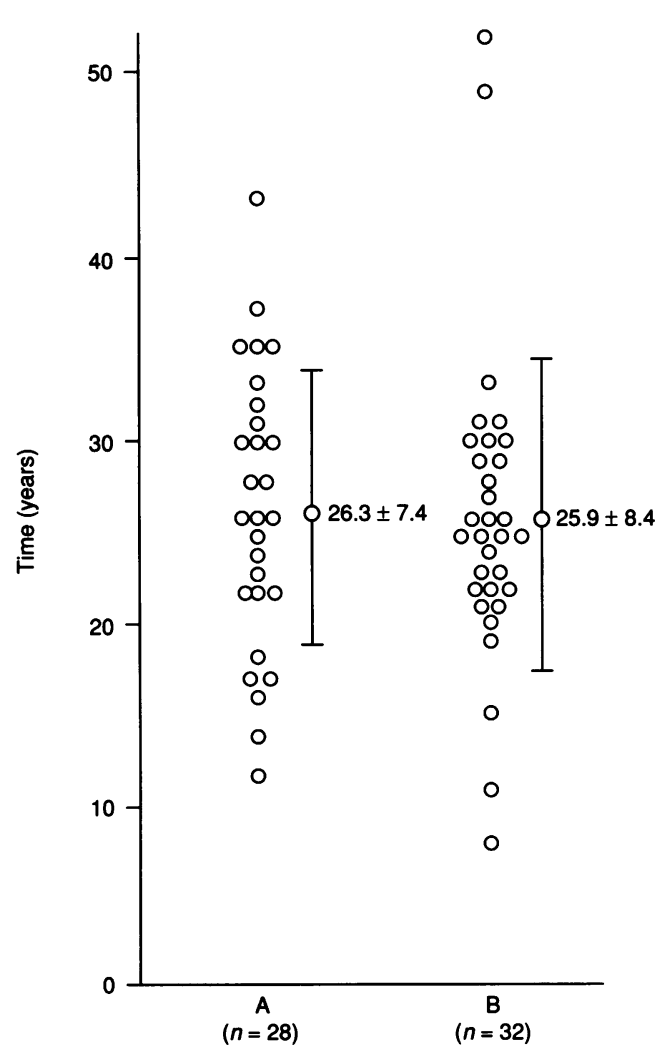

Figure 5 Duration from blood transfusion to hepatocellular carcinoma in (a) patients initially diagnosed with cirrhosis; and (b) patients with liver cancer at first examination.

and most progress to cirrhosis of the liver and liver cancer. Compared with hepatitis B, therefore, patients with hepatitis $\mathrm{C}$ have a poor prognosis. $^{3-5}$

Figure 5 shows the results of a survey of patients with transfusion associated $\mathrm{HCV}$ infection: (a) 28 cases of liver cancer pro- gressing from cirrhosis; and (b) 32 cases of liver cancer diagnosed at the first examination. In both groups, $80 \%$ of patients progressed to liver cancer 20-35 years after transfusion (average 26 years). Thus, the average duration of chronic $\mathrm{HCV}$ infection is about 30 years.

\section{Conclusion}

In Japan, about $2 \cdot 3$ million people are infected with the hepatitis $\mathrm{C}$ virus. Of these, about $70 \%$ are $\mathrm{HCV}$ carriers; the remaining $30 \%$ are positive for anti-HCV core antibody alone which, together with HCV-RNA negativity on PCR, may be evidence of past HCV infection. Once someone is chronically infected with $\mathrm{HCV}$, there is little chance of spontaneous remission and the disease gradually worsens over long periods of time. The disease progresses slowly in young patients, while the elderly show a rapid progress from chronic hepatitis $\mathrm{C}$ to liver cirrhosis and liver cancer. The clinical course lasts an average of 30 years from infection to cirrhosis and possibly hepatocellular carcinoma. As infection with $\mathrm{HCV}$ can lead to liver cancer, it is important to diagnose these patients early and to start effective treatment.

1 Choo Q-L, Kuo G, Weiner AJ, et al. Isolation of a cDNA clone derived from a blood-borne non-A, non-B viral hepatitis genome. Science 1989; 244: 359-61.

2 Kuo G, Choo Q-L, Alter HJ, et al. An assay for circulating antibodies to a major etiologic virus of human non-A, non-B, hepatitis. Science 1989; 244: 362-4.

3 Yano $M$, Yatsuhashi $H$, Inoue O, Koga $M$. Epidemiology of hepatitis $C$ virus in Japan: Role in chronic liver disease of hepatitis C virus in Japan: Role in chronic liver disease and hepatocellular carcin

4 Yatsuhashi $\mathrm{H}$, Inoue $\mathrm{O}$, Koga $\mathrm{M}$, et al. Comparison of hepatitis $C$ virus markers in patients with NANB hepatitis. F Virol Methods 1992; 37: 13-22.

5 Inoue $O$, Koga $M$, Yatsuhashi $H$, Yano $M$. The natural course of anti-HCV positive non-A, non-B chronic hepatitis in comparison with that of type B chronic hepatitis: a clinical and histological investigation. Viral hepatitis $C, D, E$ 1991: 103-7. 